\title{
Efficiency of surface modified Ti coated with copper nanoparticles to control marine bacterial adhesion under laboratory simulated conditions
}

\author{
CHOKKALINGAM PRIYA, GANESSIN ARAVIND and WILSON RICHARD THILAGARAJ* \\ Department of Biotechnology, School of Bioengineering, SRM University, Chennai 603 203, Tamilnadu, India
}

MS received 17 June 2015; accepted 29 October 2015

\begin{abstract}
Titanium (Ti) used as condenser material in nuclear power plants encounter severe biofouling in marine environment which in turn affects the efficiency of the metal. To reduce the biofouling by marine microorganisms, surface modification of the $\mathrm{Ti}$ was carried out by anodization process to obtain nanotubes $\left(\mathrm{TiO}_{2}\right.$-NTs). The electrolyte solution containing $1 \%$ of ammonium fluoride resulted in uniform growth of $\mathrm{TiO}_{2}-\mathrm{NTs}$. $\mathrm{TiO}_{2}-\mathrm{NTs}$ were further coated with chemically synthesized copper nanoparticles (NT-CuNP) using 3-amino propyl triethoxy silane as a coupling agent. NT-CuNP was characterized by field-emission scanning electron microscopy (FE-SEM), energydispersive spectroscopy and $\mathrm{X}$-ray diffraction. The stability of the coating was determined by the amount of $\mathrm{Cu}^{+}$ ions released into the surrounding using AAS. The microbial adhesion on the surface of $\mathrm{Ti}_{1} \mathrm{TiO}_{2}$-NTs and NT-CuNP coupons were evaluated by sea water exposure studies using total viable count method and also characterized by FE-SEM for any morphological changes. The NT-CuNP coupons show a $60 \%$ reduction in microbial adhesion when compared to control Ti coupons.
\end{abstract}

Keywords. Titanium; surface modification; copper nanoparticles; 3-amino propyl triethoxy silane; microbial adhesion.

\section{Introduction}

Titanium (Ti) is widely used as heat exchanger material in many nuclear power plants because of its characteristic properties like light weight, high strength to weight ratio and its corrosion resistant properties which makes it an edge over other metals. Conversely, the inertness of $\mathrm{Ti}$ surface and its excellent biocompatibility makes it highly susceptible to biofouling when used as condenser material in aquatic environments [1]. According to Satpathy [2], because of the attachment of biofoulants the performance of heat exchangers declines. The speed of water flow and their carrying capacity were reduced significantly owing to biofouling growth along the pipe line systems. Unfortunately, the inner wall of all cooling system remains an appropriate substrate for marine growth. Therefore a common solution for biofouling problem is not reasonable relating to the complexity of the nature of the aquatic life, which colonizes a submerged surface. The combination of mechanical and chemical treatments like sponge ball cleaning, back washing and chlorination is commonly used as the fouling control strategies in cooling water systems [3]. However, the practical experience has shown that no routine treatment regime can successfully keep the condenser system clean over a period of years [4]. According to Vishwakarma et al [1] surface modification of the materials is an enviable process for controlling the microbial attachment, since the initial adhesion and further growth

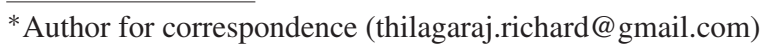

of microbial cells on the materials is influenced by the surface properties of the substratum. Hence the surface modification of $\mathrm{Ti}$ was carried out in this study to decrease the microbial attachment.

Several methods like sol-gel transcription [5,6], deposition on a nanoporous alumina template [7-10], seeded growth mechanism [11] and hydrothermal processes [12-14] were adopted for surface modification of Ti which results in $\mathrm{TiO}_{2}$ nanotube $\left(\mathrm{TiO}_{2}-\mathrm{NT}\right)$ arrays growth on its surface. Among these, the electrochemical anodization method has attracted the most attention owing to its ability to produce integrative, vertically oriented and highly ordered nanotube arrays with controllable dimensions in an economical and efficient manner [15-19] has achieved self-organized porous $\mathrm{TiO}_{2}-\mathrm{NTs}$ by anodizing Ti-based alloy in an acidic and fluoride-based electrolyte. $\mathrm{TiO}_{2}-\mathrm{NTs}$ have wide range of applications from water and air purification to tissue engineering and molecular filtration [20]. In addition $\mathrm{TiO}_{2}-\mathrm{NTs}$ reduces bacterial adhesion remarkably which in turn helps to decrease the effect of biofouling [21].

To increase the efficiency of $\mathrm{TiO}_{2}$-NTs against bacterial adhesion, nanoparticles having bactericidal effects can be incorporated into it. According to Morones et al [22] the bactericidal activity of the metal nanoparticles is not only due to the release of metal ions into the solution rather it interacts closely with microbial membranes with their attributes of small size and high surface to volume ratio. Many surfaces can be coated with immobilized metal nanoparticles possessing bactericidal activity and can find application in 
various fields like medical instruments and devices, water treatment and food processing. For better utilization of antimicrobial activity the metal nanoparticles may be combined with polymers to form composites [23]. Our previous study also proved the anti-biofouling property of surface modified $\mathrm{Ti}$ coated with silver nanoparticles [24]. Viswakarma et al [1] has confirmed that thin films of $\mathrm{Cu}$ on Ti surface decrease the bacterial adhesion and also Macak et al [25] have showed that using the self-doping and electrodeposition technique $\mathrm{TiO}_{2}$-NTs can be filled with copper for antibacterial purpose. Hence the present study deals with the surface modification of Ti which includes the growth of nanotubes and the subsequent coating of CuNPs on its surface to reduce the effect of biofouling and to increase the efficiency of the metal.

\section{Experimental}

\subsection{Synthesis of $\mathrm{TiO}_{2}-\mathrm{NTS}$}

The commercially pure Ti coupons (99.9\% purity) of size $30 \mathrm{~mm} \times 20 \mathrm{~mm} \times 3 \mathrm{~mm}$ were purchased and polished initially with 600 and finally with 1200-grit paper, and then washed with acetone and distilled water in an ultrasonic cleaner. Initially the $\mathrm{Ti}$ coupons were etched in a solution containing $\mathrm{HNO}_{3}: \mathrm{HF}: \mathrm{H}_{2} \mathrm{O}(60: 25: 15)$ for $10 \mathrm{~s}$ to remove the airformed oxide layer. The polished Ti coupons were anodized in an electrolyte solution containing $0.2-1.2 \%$ ammonium fluoride using direct-current power-supply unit. The voltage and current density were $20 \mathrm{~V}$ and $30 \mathrm{~mA}$, respectively, applied for $10 \mathrm{~min}$ at room temperature. The $\mathrm{Ti}$ coupon was used as anode and stainless steel was used as cathode. Finally, the anodized Ti was annealed at $500^{\circ} \mathrm{C}$ for $2 \mathrm{~h}$ in order to convert amorphous form of titanium to crystalline form [26]. The nanotubes formed on the Ti surface $\left(\mathrm{TiO}_{2}-\mathrm{NTs}\right.$ ) were characterized using FE-SEM (FEI Quanta FEG-200). The phase change from amorphous to crystalline anatase phase during anodization was observed using XRD (PANalytical Instruments) operating with $\mathrm{CuK} \alpha$ radiation, $\lambda=1.5406 \AA$ at a scan rate $(2 \theta)$ of $0.05^{\circ} 2 \mathrm{~s}^{-1}$ with the accelerating voltage of $45 \mathrm{kV}$ at the applied current of $40 \mathrm{~mA}$.

\subsection{Synthesis of CuNPs}

Copper nanoparticles (CuNP) were synthesized by the chemical reduction method using sodium borohydride. Briefly, to the solution of $0.02 \mathrm{M}$ ascorbic acid $0.01 \mathrm{M} \mathrm{CuSO}_{4} \cdot 5 \mathrm{H}_{2} \mathrm{O}$ was added and allowed for strong stirring. Polyvinyl chloride (PVP) was added to the above solution keeping the molar ratio of $[\mathrm{PVP}] /\left[\mathrm{Cu}^{2+}\right]=0.15$. One molar $\mathrm{NaOH}$ solution was used for adjusting the $\mathrm{pH}$ of the solution up to 12 . The solution was stirred at room temperature for an hour and finally $0.1 \mathrm{M} \mathrm{NaBH}_{4}$ was added [27]. The surface plasmon resonance peak exhibited by as-prepared CuNPs was examined using UV-VIS spectrophotometer (Amersham Biosciences) in the wavelength range of 300-700 $\mathrm{nm}$.

\subsection{Coating of CuNPs on $\mathrm{TiO}_{2}-\mathrm{NT}$ surface}

$\mathrm{TiO}_{2}$-NTs coupons were silanized in $2 \%$ ethanolic solution of 3-aminopropyl tri ethoxy silane (APTES) for about $1.5 \mathrm{~h}$ followed by incubation in CuNP solution for $2 \mathrm{~h}$ in order to get CuNP-coated $\mathrm{TiO}_{2}-\mathrm{NTs}$ (NT-CuNP) [28]. After which the coupons were rinsed and dried. The distribution of CuNPs on $\mathrm{TiO}_{2}$-NTs was analysed using FE-SEM and EDS.

\subsection{Copper ions release rate}

To determine the release rate of $\mathrm{Cu}^{+}$ions, the NT-CuNP coupons were immersed in seven conical flasks individually containing $50 \mathrm{ml}$ of sea water for a week in a shaker at 50 rpm to induce the natural tide effect as in sea. Each day a coupon was taken out and the solution was diluted enough to analyse the concentration of $\mathrm{Cu}^{+}$ions released from the $\mathrm{Ti}$ coupon using AAS. The experiment was done in triplicates.

\subsection{Lab scale sea water exposure studies of control and experimental Ti coupons}

Ti-C, $\mathrm{TiO}_{2}-\mathrm{NTs}$ and NT-CuNPs coupons were tied with $\mathrm{Ti}$ frame and exposed in a tub containing sea water with small pump attached to make sure the continuous water flow on the coupons to study the antibiofouling effect of the nanoparticles-coated coupons. Sea water was changed for once in 2 weeks and the exposure study was conducted for about 2 months. The source of sea water was the coastal water belonging to the Bay of Bengal. The coupons were taken out at 1 st and 2 nd month of exposure and sonicated in waterbath sonicater for $10 \mathrm{~min}$ in $15 \mathrm{ml}$ of sterile phosphate buffer $\left(\mathrm{KH}_{2} \mathrm{PO}_{4} 0.0425 \mathrm{~g} \mathrm{l}^{-1}, \mathrm{MgCl}_{2} 0.19 \mathrm{~g} \mathrm{l}^{-1}\right)$. The sonicated buffer was treated as bacterial suspension. The bacterial suspension was then serially diluted and $0.1 \mathrm{ml}$ of each dilution was plated on Zobell's Marine agar (ZMA; Hi Media M384). The plates were incubated at $37^{\circ} \mathrm{C}$ for $24 \mathrm{~h}$ and the total viable count (TVC) was estimated [29]. The sonicated Ti coupons were also analysed using FE-SEM for any morphological changes.

\subsection{Statistical analysis}

$\mathrm{Cu}^{+}$ions release rate study and seawater exposure experiments with the coupons were carried out in triplicates to validate the reproducibility of the experiments and the data presented are the means of three independent experiments. The data were analysed statistically by Student's $t$-test to calculate $p$-value and $p<0.01$ were taken as significant and standard errors of the mean was calculated.

\section{Results and discussion}

\subsection{Characterization of $\mathrm{TiO}_{2}-\mathrm{NT}$ surface by $\mathrm{FE}$ - SEM analysis}

Figure 1a-f shows the nanotube growth on Ti surface by anodization in varying concentration of $\mathrm{NH}_{4} \mathrm{~F}(0.2-1.2 \%)$. 

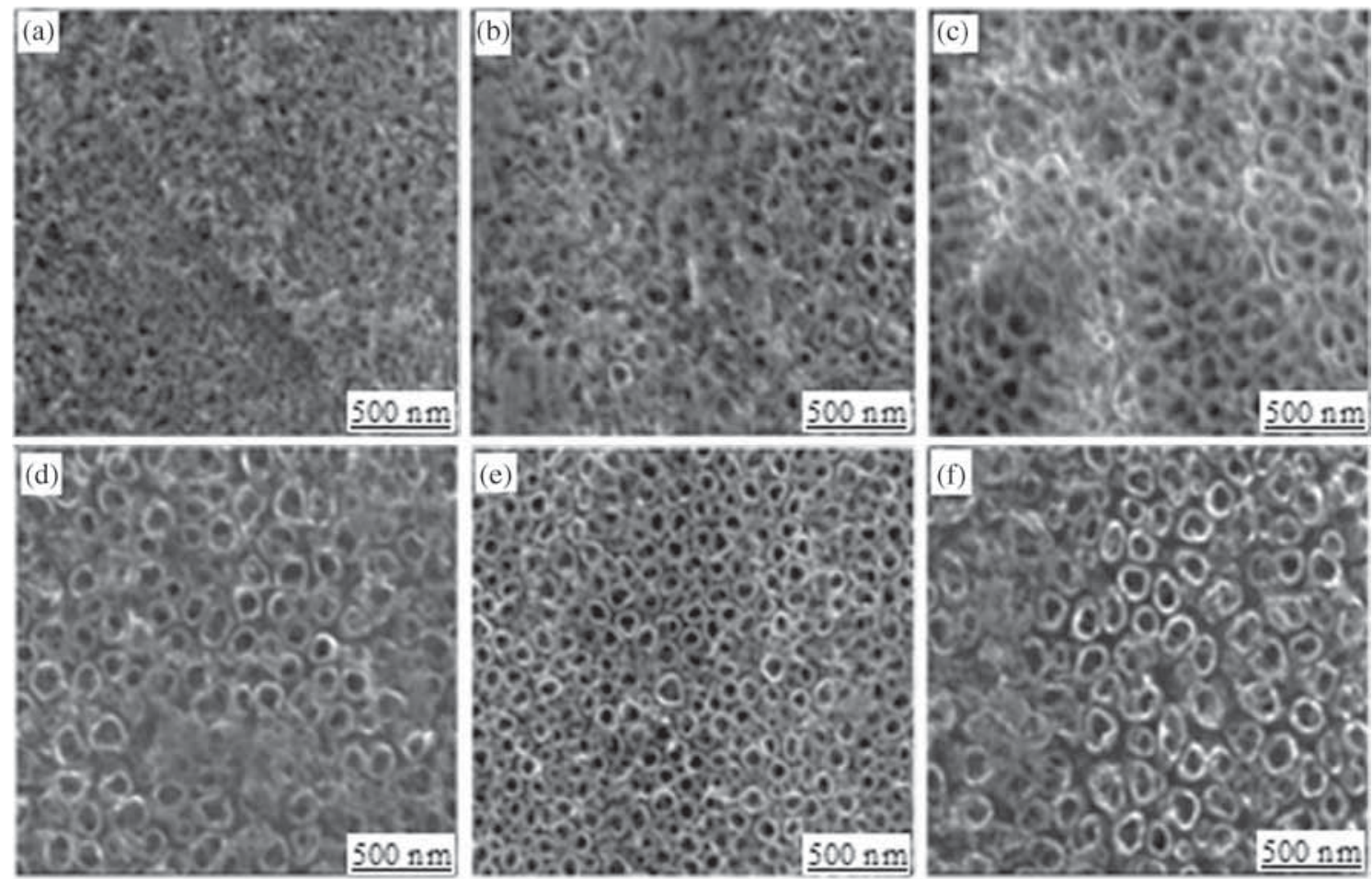

Figure 1. FE-SEM images of Ti surface anodized in varying concentrations of $\mathrm{NH}_{4} \mathrm{~F}$ : (a) 0.2, (b) 0.4, (c) 0.6, (d) 0.8, (e) 1.0 and (f) $1.2 \%$.

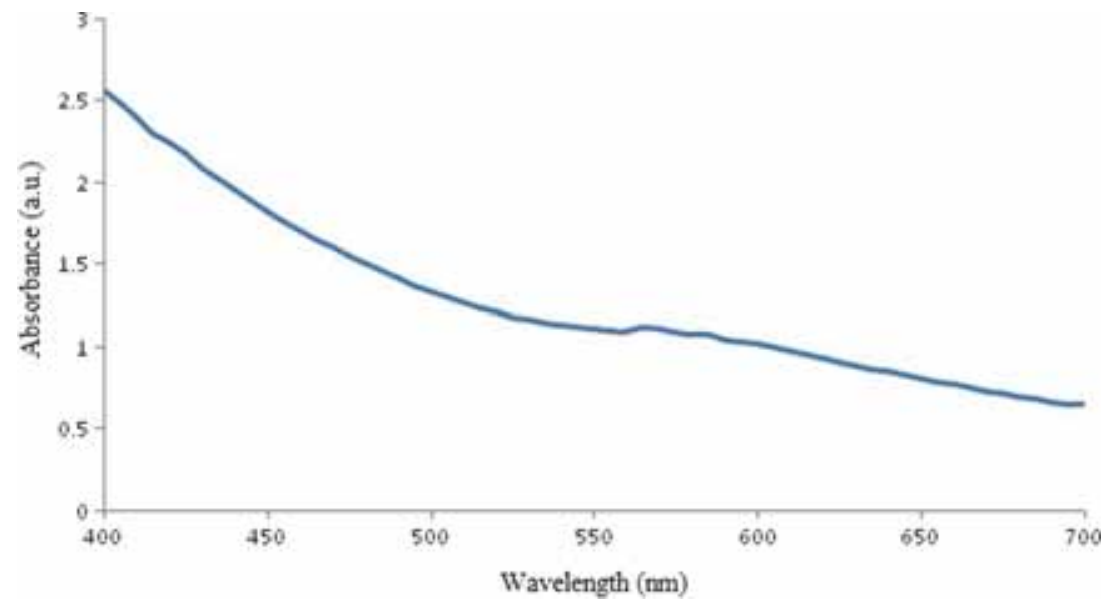

Figure 2. UV-Vis spectrum of copper nanoparticles.

Irregularities of nanotube structure were seen in below and above $1 \%$ of $\mathrm{NH}_{4} \mathrm{~F}$ concentration. The reason behind the nanotube formation are (i) formation of thin oxide layer at the metal surface due to the interaction of the metal with $\mathrm{O}^{2-} / \mathrm{OH}^{-}$ions; (ii) electric field associate dissolution of the oxide layer resulting in the formation of pits; and (iii) chemical dissolution of these pits into nanotube array by $\mathrm{F}$ ions present in the electrolyte solution [26]. It was clear from the FE-SEM image that the growth of nanotube arrays of even size was achieved in $1 \% \mathrm{NH}_{4} \mathrm{~F}$ concentration.

\subsection{Characterization of CuNPs}

Figure 2 shows the UV-VIS absorption spectra of synthesized CuNPs in the region of 300-700 $\mathrm{nm}$. The absorption spectra shows a prominent symmetric peak around 570 $\mathrm{nm}$, which is due to the strong interaction of the copper nanoparticles with light occurs because of the conduction electrons on the metal surface undergo a collective oscillation when excited by light at this specific wavelength [30]. This is the characteristic surface plasmon resonance of copper nanoparticles prepared. The synthesized CuNPs were coated on $\mathrm{TiO}_{2}$-NTs surface with the help of coupling agent silane. 


\subsection{Characterization of NT-CuNPs coupons}

Deposition of CuNPs on $\mathrm{TiO}_{2}$-NTs surface is represented by FE-SEM image in figure $3 \mathrm{c}$, whereas figure $3 \mathrm{a}$ and $\mathrm{b}$ represents FE-SEM image of control Ti coupon and anodised $\mathrm{Ti}$ in $1 \% \mathrm{NH}_{4} \mathrm{~F}$ solution, respectively. The covalent bond between $\mathrm{TiO}_{2}$-NTs and as-prepared CuNP is achieved by silane which serves as a coupling agent. The presence of $\mathrm{CuNP}$ on $\mathrm{TiO}_{2}$-NTs surface was also confirmed by EDS analysis and the result shows the presence of silane and copper of remarkable concentration along with $\mathrm{Ti}$ (figure 5).

\subsection{XRD analysis of Ti-C, $\mathrm{TiO}_{2}-\mathrm{NT}$ s and NT-CuNP coupons}

In the XRD analysis, figure 4a shows only the typical refraction peaks for Ti before it was subjected to surface modification. After anodization, upon heat treatment at higher temperature the amorphous $\mathrm{TiO}_{2}$ crystallizes into anatase and further increase in temperature anatase may convert to rutile phase [31]. Thus, the $\mathrm{XRD}$ analysis of $\mathrm{TiO}_{2}$ NT coupons annealed at $500^{\circ} \mathrm{C}$ has shown the peaks at $2 \theta=25.37^{\circ}, 35.20^{\circ}, 53.12^{\circ}, 71.67^{\circ}$ attributed to (101), (103), (105), (220) lattice planes of anatase, respectively,
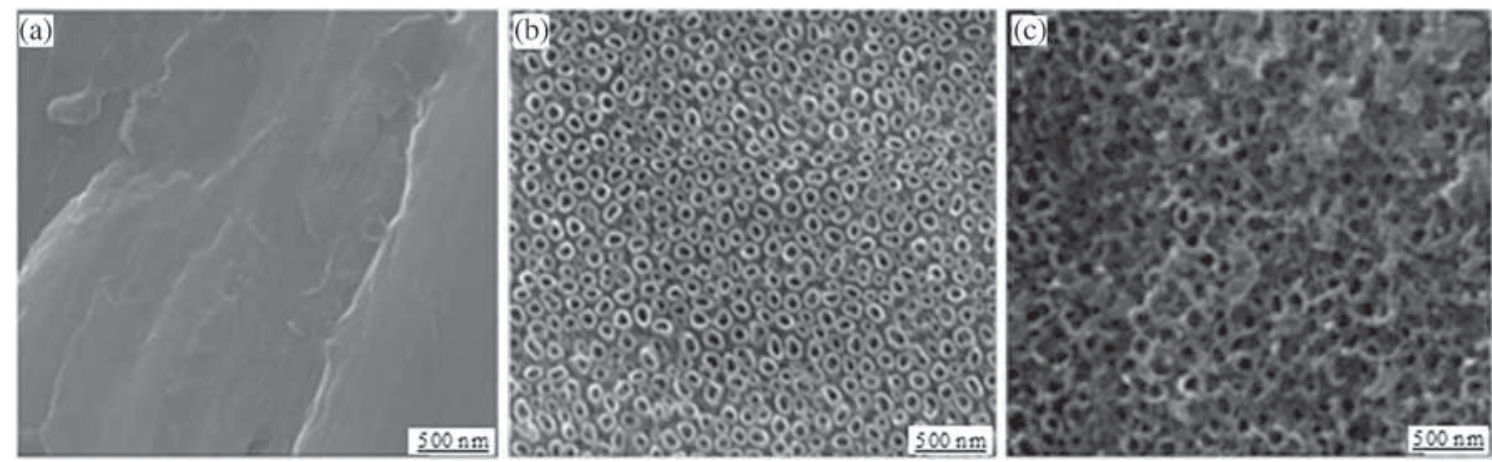

Figure 3. FE-SEM images of (a) Ti-C, (b) $\mathrm{TiO}_{2}-\mathrm{NT}$ and (c) NT-CuNPs.

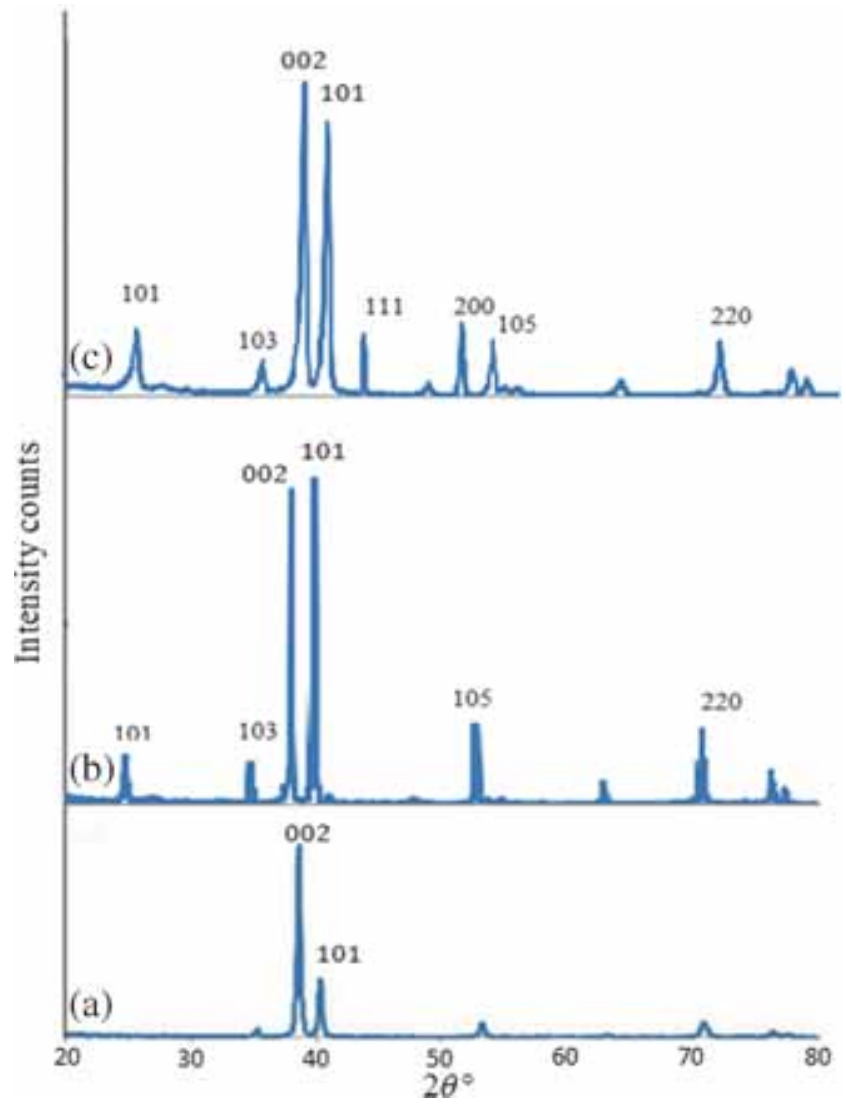

Figure 4. XRD image of (a) Ti-C, (b) $\mathrm{TiO}_{2}-\mathrm{NT}$ s and (c) NTCuNPs. 
with reference to JCPDS card no. 21-1272, figure 4b. For NT-CuNP coupons, the peaks at $43.2^{\circ}$ and $50.6^{\circ}$ were seen along with the anatase peaks of $\mathrm{Ti}$, were corresponds to the (111) and (200) crystal planes of $\mathrm{Cu}$, respectively, with reference to JCPDS card no. 040836, figure 4c. The calculated particle size of as-deposited copper nanoparticles using the Scherrer formula was around 30 $\mathrm{nm}$. The XRD and FE-SEM result shows that the synthesized CuNPs were coated evenly on the surface of $\mathrm{TiO}_{2}-\mathrm{NTs}$ (figure 5).

\section{$3.5 \mathrm{Cu}^{+}$ions release rate analysis}

The silanization technique was adopted for coating CuNPs on the surface of $\mathrm{TiO}_{2}-\mathrm{NT}$. Since previous research study shows that the surface-grafted polymerization of PVP was achieved on the surface of silane modified $\mathrm{Fe}_{3} \mathrm{O}_{4}$ nanoparticles
[32], in our study stability of the CuNP coating on $\mathrm{TiO}_{2}-\mathrm{NTs}$ surface is achieved by silane which acts as a coupling agent between the hydroxyl ends of the metal surface and the polymer surrounding CuNP. At the end of the 7th day, controlled release of $\mathrm{Cu}^{+}$ions from the NT-CuNP coupons treated with silane was observed with $76 \pm 5.5 \mathrm{ppb}$. Whereas, NT-CuNP coupons treated without silane shows $145 \pm 17.2$ $\mathrm{ppb}$ of $\mathrm{Cu}^{+}$ions release leaching the most (figure 6). Hence, $\mathrm{Cu}^{+}$release rate of NT-CuNP coupons treated with silane was significantly very less than without silane treatment $(p<0.01)$. Finally, NT-CuNP coupons treated with silane for coating were used for sea water exposure studies.

\subsection{Sea water exposure studies}

Figure 7 shows the total viable count study of $\mathrm{Ti}-\mathrm{C}, \mathrm{TiO}_{2}$ NTs and NT-CuNP at 1st and 2nd month of sea water

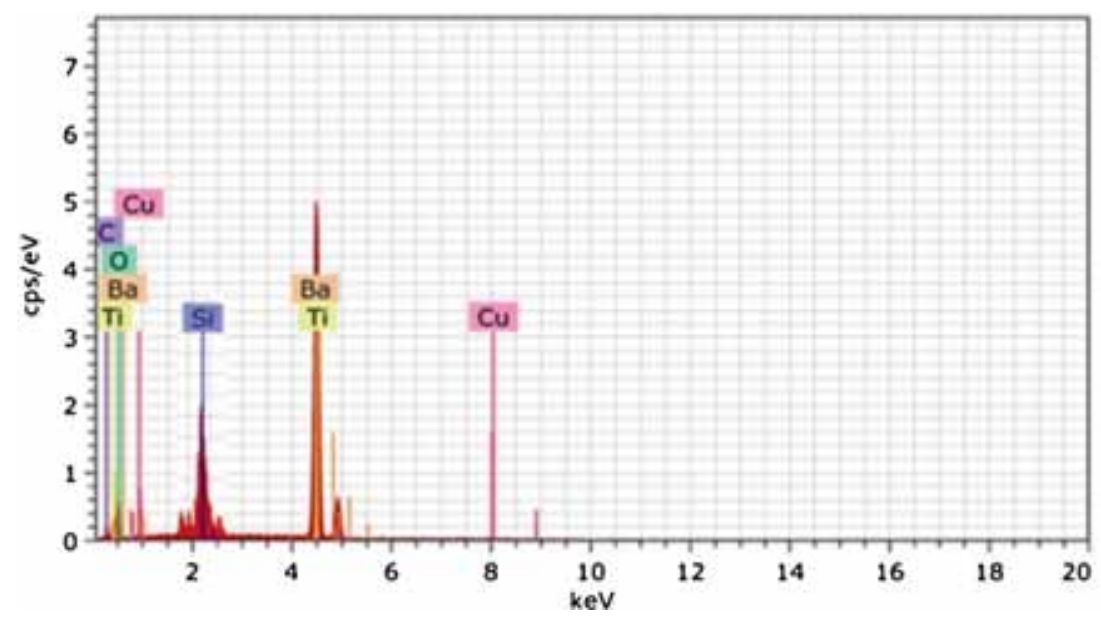

Figure 5. EDS result of NT-CuNPs.

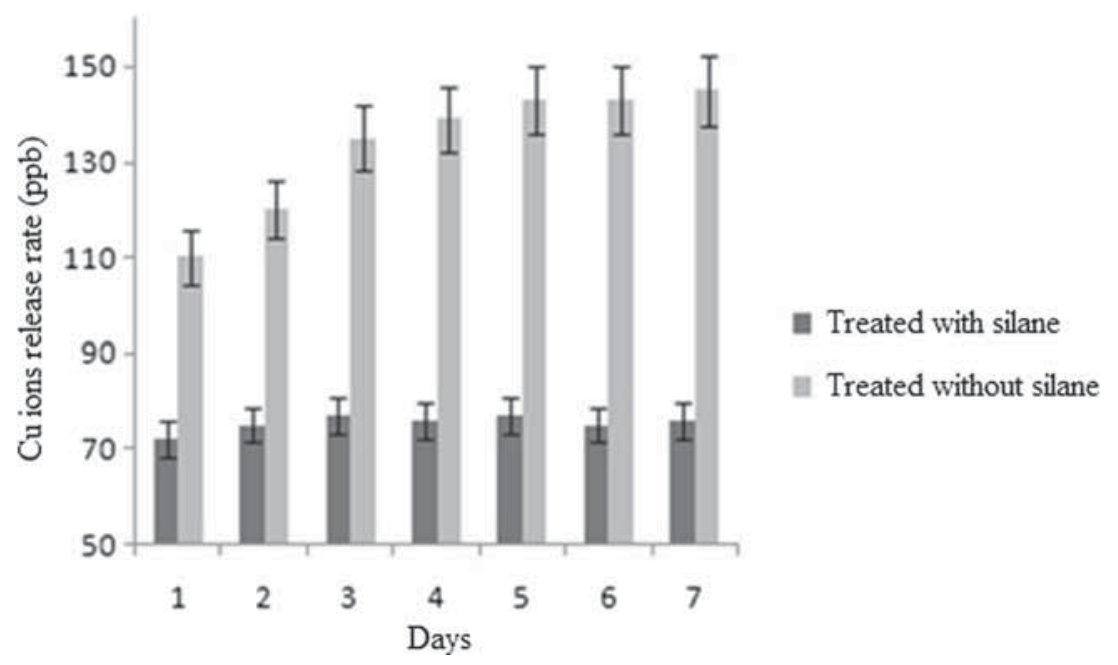

Figure 6. $\mathrm{Cu}^{+}$ions release rate from NT-CuNP coupons treated with and without silane. Means $\pm \mathrm{SE}$ are shown $(n=3)$. 


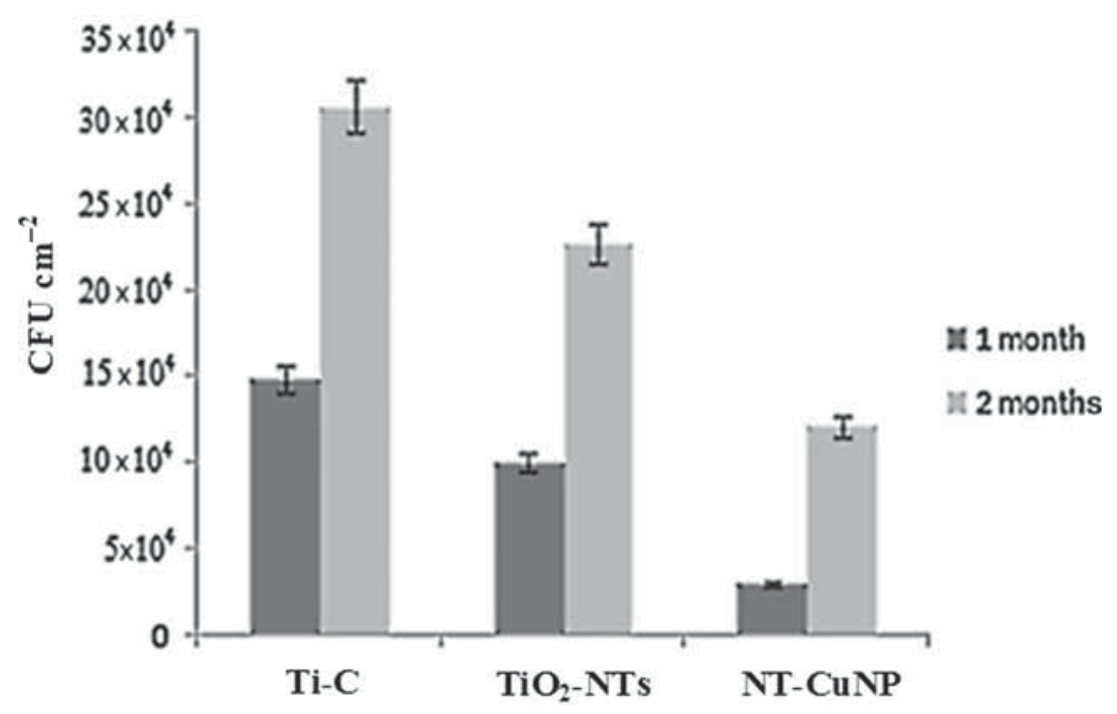

Figure 7. Total viable count data of Ti-C, $\mathrm{TiO}_{2}-\mathrm{NTs}$ and NT-CuNP coupons exposed in sea water for 1 and 2 months. Means \pm SE are shown $(n=3)$.
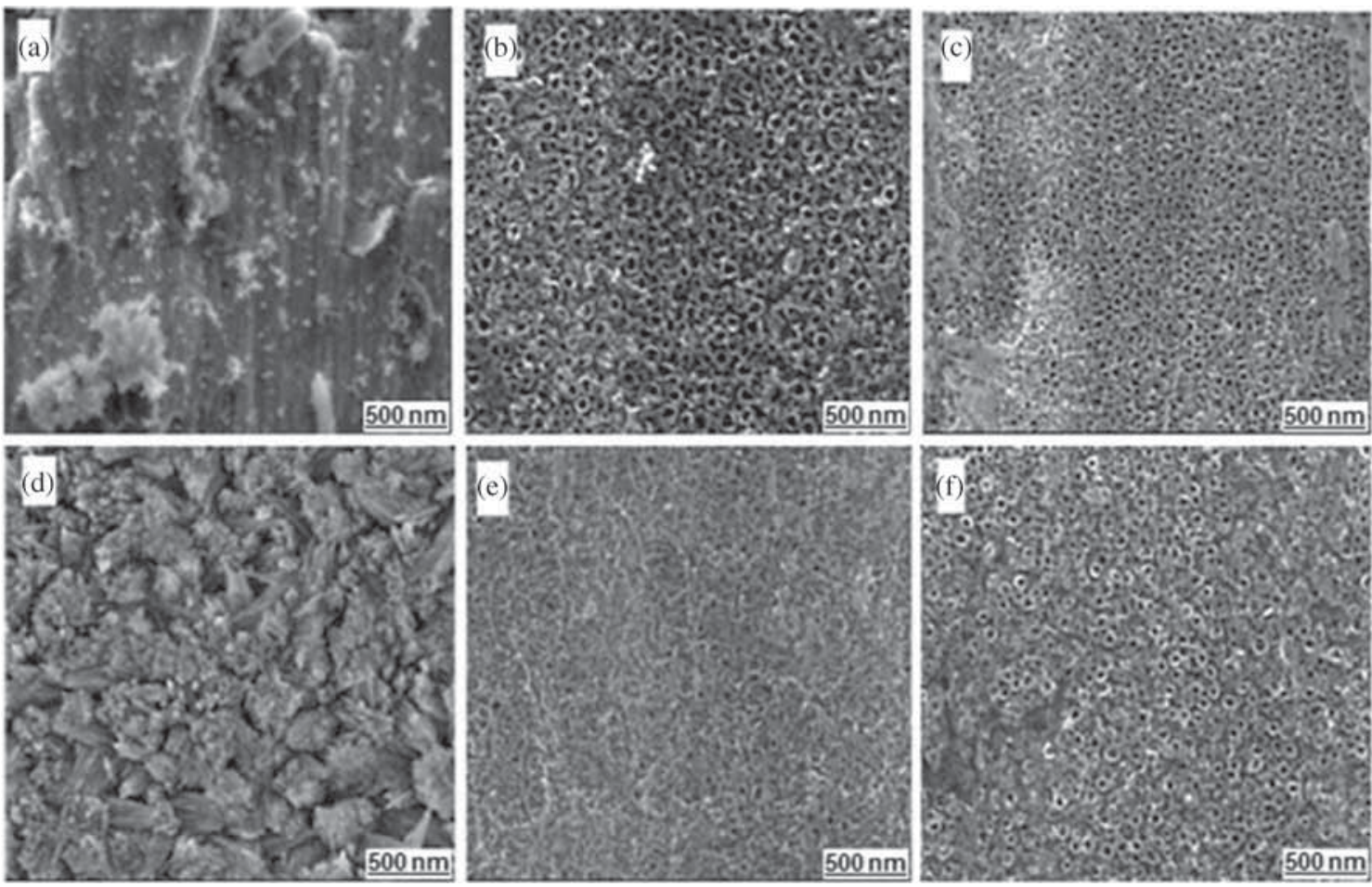

Figure 8. FE-SEM images of (a) Ti-C, (b) $\mathrm{TiO}_{2}-\mathrm{NTs}$ and (c) NT-CuNP coupons exposed in sea water for 1 month and (d) Ti-C, (e) $\mathrm{TiO}_{2}$-NTs and (f) NT-CuNP coupons exposed in sea water for 2 months.

exposure. The experiments were done in triplicates. The results show increased bacterial adhesion on the coupons in the order of Ti-C $>\mathrm{TiO}_{2}$-NTs $>$ NT-CuNPs. It is more evident from the result that NT-CuNPs coupons exhibit $60 \%$ decrease in bacterial adhesion when compared with control coupons. This is mainly achieved by the presence of copper ions which express the antibacterial activity by attaching to and penetrating the bacterial cell wall and affecting the cellular activity due to their toxicity. Moreover, the negative charge of the surface membrane of bacteria and positive charge of copper ions can easily bind, thereby enhancing the antibacterial activity and in turn reduces the bacterial adhesion on the surface of the coupon [33].

Figure 8 shows the FE-SEM images of control and experimental $\mathrm{Ti}$ coupons after the sea water exposure period. It 
is clearly seen from the figure $8 \mathrm{a}$ and $\mathrm{d}$ that the control $\mathrm{Ti}$ coupon without any surface modification encountered severe biofouling at the end of 2nd month. Whereas $\mathrm{TiO}_{2}$-NTs (figure $8 \mathrm{~b}$ and e) and NT-CuNP (figure 8c and f) coupons shows reduced bacterial adhesion at 1st and 2 nd month of exposure in sea water. Since CuNPs were coated onto the nanotubes via silane, a controlled release of $\mathrm{Cu}^{+}$ions into the sea water is achieved and the stability of the coating remains stable for longer time to reduce the bacterial adhesion on the surface of the metal, hence the rate of biofouling is also reduced. Also the efficiency of the metal will be increased when used as a condenser material in marine environments.

\section{Conclusion}

This research study mainly focused on the surface modification of Ti metal to reduce the effect of biofouling mainly for condenser application in sea water environment. In this research work, $\mathrm{TiO}_{2}$-NTs were grown by the electrochemical anodization technique and to that chemically synthesized copper nanoparticles were coated using silane (APTES). This bonding promotes controlled release of $\mathrm{Cu}^{+}$ions into the sea water. The decrease in bacterial adhesion on $\mathrm{TiO}_{2}-$ NT coupon shows that the nanotubes itself has antibiofouling property. In addition the coating of CuNP, which is having bactericidal effect in nature provides longer protection of the metal against biofouling and consecutively increases the lifetime of the metal in the sea water environment.

\section{References}

[1] Vishwakarma V, Josephine J, George R P, Krishnan R et al 2009 Biofouling 25705

[2] Satpathy K K 1990 Proceedings of Specialists Meeting on Marine Biodeterioration with Special Reference to Power Plant Cooling System (Kalpakkam, Tamil Nadu, India: WSCL) p 153

[3] Howell A and Saxon G 2005 Am. Soc. Mech. Eng. 719

[4] Characklis W G 1990 Characklis W G, Marshall K C (eds), Biofilms (New York: John Wiley \& sons) p 195

[5] Jung J H, Kobayashi H, Van Bommel K J C, Shinkai S and Shimizu T 2002 Chem. Mater. 141445

[6] Kobayashi S, Hamasaki N, Suzuki M, Kimura M, Shirai H and Hanabusa K 2002 J. Am. Chem. Soc. 1246550

[7] Hoyer P 1996 Langmuir 121411

[8] Lakshmi B B, Dorhout P K and Martin C R 1997 Chem. Mater. 9857

[9] Imai H, Takei Y, Shimizu K, Matsuda M and Hirashima H 1999 J. Mater. Chem. 92971
[10] Michailowski A, AlMawlwai D, Cheng G S and Moskovits M 2001 Chem. Phys. Lett. 3491

[11] Tian Z R R, Voigt J A, Liu J, McKenzie B and Xu H F 2003 J. Am. Chem. Soc. 12512384

[12] Kasuga T, Hiramatsu M, Hoson A, Sekino T and Niihara K 1998 Langmuir 143160

[13] Chen Q, Zhou W Z, Du G H and Peng L H 2002 Adv. Mater. 14 1208

[14] Yao B D, Chan Y F, Zhang X Y, Zhang W F, Yang Z Y and Wang N 2003 Appl. Phys. Lett. 82281

[15] Gong D, Grimes C A, Varghese O K, Hu W, Singh R S, Chen $\mathrm{Z}$ and Dickey E C 2001 J. Mater. Res. 163331

[16] Mor G K, Vargese O K, Paulose M, Mukherjee N and Grimes C A 2003 J. Mater. Res. 182588

[17] Zhoa J, Wang X, Sun T and Li L 2005 Nanotechnology 16 2450

[18] Zwilling V, Aucouturier M and Darque-Ceretti E 1999 Electrochim. Acta 45921

[19] Zwilling V, Darque-Ceretti E, Boutry-Forveille A, David D, Perrin M Y and Aucouturier M 1999 Surf. Interface Anal. 27 629

[20] Rohani S and Ahmed-El-Ruby 2009 Chem. Eng. Trans. 17 963

[21] Del Curto B, Brunella M F, Giordano C, Pedeferri M P, Valtulina V, Visai L and Cigada A 2005 Int. J. Artif. Organs 28718

[22] Morones J R, Elechiguerra J L, Camacho A, Holt K, Kouri J B, Ramirez J T et al 2005 Nanotechnology 162346

[23] Ruparelia J P, Chatterjee A K, Duttagupta S P and Mukherji S 2008 Acta Biomater. 4707

[24] Priya C, Aravind G and Thilagaraj W R 2014 Res. J. Chem. Environ. 1876

[25] Macak J M, Gong B G, Hueppe M and Schmuki P 2007 Adv. Mater. 193027

[26] Alivov Y, Fan Z Y and Johnstone D 2009 J. Appl. Phys. 106 034314

[27] Dang T M D, Le T T, Fribourg-Blanc E and Dang M C 2011 Adv. Nat. Sci.: Nanosci. Nanotechnol. 2025004

[28] Juan L, Zhimin Z, Anchun M, Lei L and Jingchao Z 2010 Int. J. Nanomed. 5261

[29] APHA 1989 Standard Methods for the Examination of Water and Waste Water (Washington, DC: APHA) p 182

[30] Solomon S D, Bahadory M, Jeyarajasingam A V, Rutkowsky S A, Boritz C and Mulfinger L 2007 J. Chem. Educ. 84 322

[31] Sreekantan S, Hazan R and Lockman Z 2009 Thin Solid Films 51816

[32] Arsalani N, Fattahi H and Nazarpoor M 2010 Exp. Polym. Lett. 4329

[33] Josephine J, Vishwakarma V, George R P, Kumruddin M, Kalavathi S, Manoharan N, Tyagi A K and Dayal R K 2010 Curr. Sci. 991079 